\title{
Performance of Regenerative Gas Turbine Power Plant
}

\author{
Hossin Omar ${ }^{*}$, Aly Kamel${ }^{1}$, Mohammed Alsanousi ${ }^{2}$ \\ ${ }^{1}$ Mechanical Engineering Department, University of Benghazi, Benghazi, Libya \\ ${ }^{2}$ Faculty of Engineering, University of Benghazi, Ajdabia, Libya \\ Email: ‘hussinomar.omar@gmail.com
}

How to cite this paper: Omar, H., Kamel, A. and Alsanousi, M. (2017) Performance of Regenerative Gas Turbine Power Plant. Energy and Power Engineering, 9, 136-146. https://doi.org/10.4236/epe.2017.92011

Received: July 30, 2016

Accepted: February 25, 2017

Published: February 28, 2017

Copyright (c) 2017 by authors and Scientific Research Publishing Inc. This work is licensed under the Creative Commons Attribution International License (CC BY 4.0).

http://creativecommons.org/licenses/by/4.0/

(c) (i) Open Access

\begin{abstract}
This study aims to investigate the effect of regeneration on the output power and the thermal efficiency of the gas turbine power plant. The effect of ambient air temperature, regeneration effectiveness, and compression ratio on the cycle thermal efficiency was also investigated. An existed gas turbine power plant of AL ZAWIA is used as a base in this study, and the calculations were carried out utilizing MATLAB code. This intensive parametric study was conducted based on the fundamental of thermodynamics and gas turbine relations considering the effect of the operation conditions (ambient air temperature, regeneration effectiveness and compression ratio). It was found that adding regeneration to the simple gas turbine cycle results in an increase in the thermal efficiency of cycle. It was also found that including regeneration in gas turbine cycle results in an increase in the output power of the cycle, and it results in a decrease in the exhaust gas temperature. The effect of the regeneration effectiveness was also predicted. It was found that increasing of regeneration effectiveness results in an increase in the output power of the cycle. It was also found that the cycle thermal efficiency increases with increasing of the regenerative effectiveness. The effect of ambient air temperature was also predicted. Increasing of the ambient air temperature results in a decrease in the thermal efficiency of the cycle.
\end{abstract}

\section{Keywords}

Gas Turbine, Power Plant, Thermal Analysis, Regeneration, Regeneration Effectiveness

\section{Introduction}

Increasing the thermal efficiency is the concern of many researchers in the last few decades. Increasing the thermal efficiency results in a decrease in the opera- 
tion cost by reducing the fuel consumption, which, in turn, reduces the emission of flue gases $\left(\mathrm{CO}_{\mathrm{x}}, \mathrm{NO}_{\mathrm{x}}\right)$ to the environment.

Therefore, intensive research activities have been under going to increase the thermal efficiency of thermal power generation of gas and steam turbine cycles. There are different methods are utilized to increase the thermal efficiency of the cycles. Reheating is a process utilized to increase the thermal efficiency of the gas and the steam turbine cycles. Regeneration is also a procedure utilized to increase the thermal efficiencies of both the simple gas turbine and the steam turbine cycles. Another important procedure to increase the thermal efficiency of the power plant cycle is the combined cycle, which consists of a gas turbine and a steam turbine cycles [1] [2].

Regenerative is a thermal process that utilizes the remaining heat energy of the exhaust gases leaving the gas turbine. This can be done by exchanging the heat between the exhaust hot gases exit from gas turbine with the compressed air exit from the compressor utilizing shell and tube heat exchanger [1] [2].

Several approaches are available in the literature concerning the effect of ambient air temperature inlet to the compressor on the thermal efficiency of the gas turbine cycle [3] [4] [5]. These approaches [3] [4] [5] concluded that increasing of ambient air temperature has a negative effect on the performance of gas turbine cycle. That is the thermal efficiency of the gas turbine cycle decreases with increasing of ambient air temperature. There are other approaches [6] [7] [8] available in the literature concerned the effect of the compression ratio on the gas turbine cycle.

These approaches [6] [7] [8] concluded that increasing of the compression ratio in the range of 5 to 30 results in an increase in the thermal efficiency of the gas turbine cycle.

In case of utilizing gas turbine with regeneration in a combined cycle, the thermal efficiency could reach to a higher thermal efficiency [9]. There is a similar approach [10] regarding the regenerative gas turbine cycle and it also conducted a similar parametric study as in the current approach. The difference between this paper and the previous approach [10] is the operation conditions are different.

This study aims to predict the effect of regeneration in a gas turbine cycle for certain design parameters of AL-ZAWAI station in Libya. The effect of other parameters in the performance of the gas turbine will also be performed in this study.

\section{Model Formulation}

Figure 1(a) shows the gas turbine cycle including regenerator, and Figure 1(b) shows the T-S diagram of the cycle. Regenerative is a thermodynamic process that utilizes the remaining energy in the exhaust gases from the gas turbine to heat the air entering to the gas turbine. This process can be made by heat exchange between the exhaust gases and compressed air by utilizing shell and tube heat exchanger. 


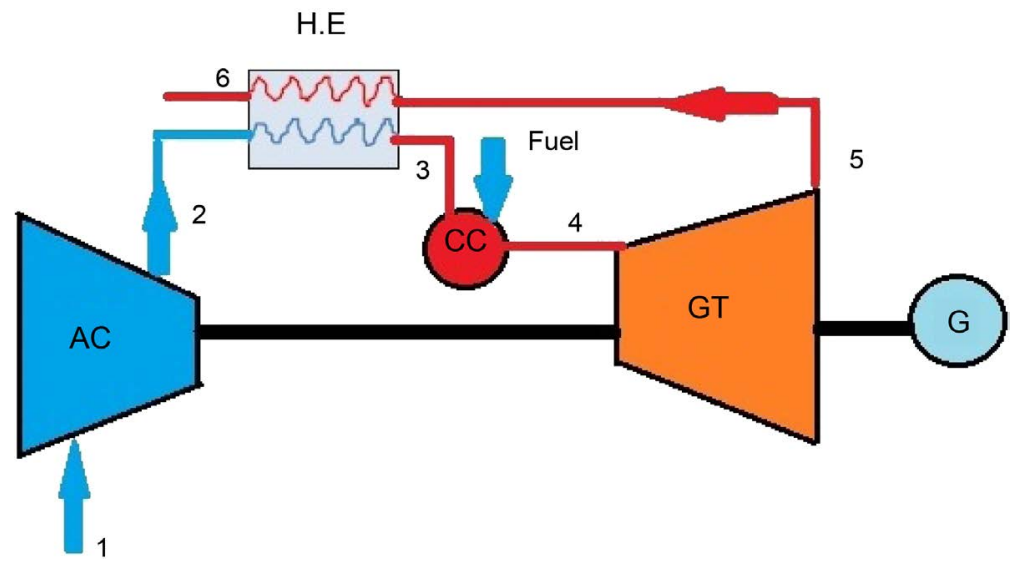

(a)

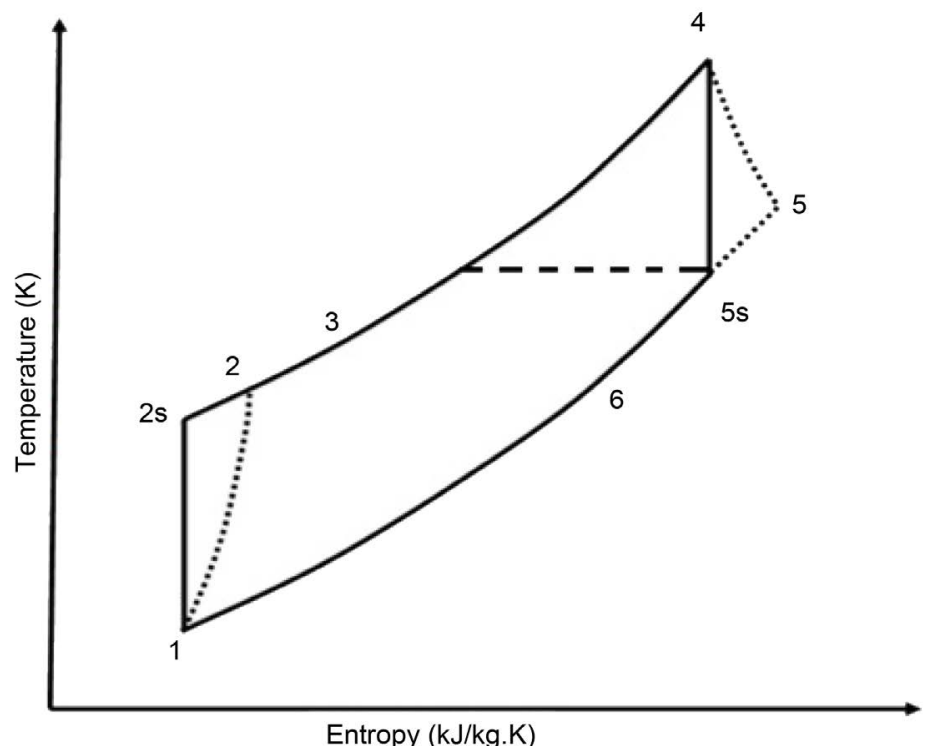

(b)

Figure 1. (a) The regenerative gas turbine cycle diagram; (b) T-S diagram [9] [10].

Using the first law of thermodynamics and the intake pressure drop $\left(\Delta P_{\text {intake }}\right)$ is taken to be 0.004 bar, the intake temperature is the same as the ambient temperature.

$$
P_{1}=P_{a t m}-\Delta P_{\text {intake }}
$$

The compressor pressure ratio $\left(r_{p}\right)$ can be defined as Equation (1):

$$
r_{p}=\frac{P_{2}}{P_{1}}
$$

where $P_{1}$ and $P_{2}$ are the compressor inlet and outlet air pressures, respectively.

The isentropic outlet temperature leaving the compressor is determined by Equation (2).

Take specific heat ratio for air $\gamma_{a}=1.4$,

$$
\frac{T_{1}}{T_{2 s}}=\left(\frac{P_{1}}{P_{2}}\right)^{\frac{\gamma_{a-1}}{\gamma_{a}}}
$$


The isentropic efficiency of the compressor expressed as Equation (3):

$$
\eta_{i s) c}=\frac{T_{2 s}-T_{1}}{T_{2}-T_{1}}
$$

where $T_{1}$ and $T_{2}$ are the compressor inlet and outlet air temperatures, respectively.

The work of the compressor $\left(W_{c}\right)$ when blade cooling is not taken into account can be calculated as Equation (5):

$$
\dot{W}_{C}=\dot{m}_{a} C p_{a}\left(T_{2}-T_{1}\right)
$$

where the specific heat of air is $C_{p a}=1.005 \mathrm{~kJ} / \mathrm{kg} \cdot \mathrm{K}$.

From the energy balance in the combustion chamber:

$$
\dot{m}_{a} C_{P a} T_{2}+\dot{m}_{f} \times C V+\dot{m}_{f} C_{P f} T_{f}=\left(\dot{m}_{a}+\dot{m}_{f}\right) C_{p g} \times T_{4}
$$

where $\dot{m}_{f}$ is the fuel mass flow rate $(\mathrm{kg} / \mathrm{s}), \dot{m}_{a}$ is the air mass flow rate $(\mathrm{kg} / \mathrm{s})$, C. $V$ is the calorific value, $T_{4}$ is turbine inlet temperature, $C_{p f}$ is the specific heat of fuel, and $T_{f}$ is the temperature of the fuel.

The specific heat of flue gas is $C p_{g}=1.07 \mathrm{~kJ} / \mathrm{kg} \cdot \mathrm{K}$, efficiency is $\eta_{C . C}=91.17 \%$, and a pressure drop $\Delta P_{C . C}=0.4785$ bar in the combustor,

$$
\eta_{C . C}=\frac{\dot{m}_{g} C p_{g} T_{4}-\dot{m}_{a} C p_{a} T_{2}}{\dot{m}_{f} \times C . V}
$$

outlet pressure from the combustor is determined from the following equation:

$$
P_{3}=P_{2}-\Delta P_{C . C}
$$

where natural gas high heating value is assumed to be around $49,291 \mathrm{~kJ} / \mathrm{kg}$ and air/fuel ratio $(A / F)$ is determined from the following equation:

$$
\frac{A}{F}=\frac{\dot{m}_{a}}{\dot{m}_{f}}
$$

The exhaust gases temperature from the $G T$ is given by Equation (10).

The isentropic outlet temperature leaving the turbine is determined by Equation (2).

Take specific heat ratio for gases $\gamma_{g}=1.3$,

$$
\frac{T_{4}}{T_{5 s}}=\left(\frac{P_{4}}{P_{5}}\right)^{\frac{\gamma_{g-1}}{\gamma_{g}}}
$$

The actual temperature drop is obtained from the definition of turbine's isentropic efficiency:

$$
\eta_{i s) g . T}=\frac{T_{4}-T_{5}}{T_{4}-T_{5 s}}
$$

The effectiveness of regenerator (heat exchanger) $(\varepsilon)$ are considered in this study.

$$
\varepsilon=\frac{T_{3}-T_{2}}{T_{5}-T_{2}}
$$


The total mass flow rate is given by:

$$
\dot{m}_{g}=\dot{m}_{a}+\dot{m}_{f}
$$

The work produced from the turbine is determined by the following equation:

$$
\dot{W}_{g \cdot T}=\dot{m}_{g} C p_{g}\left(T_{5}-T_{4}\right)
$$

The network of the GT ( $\left.W_{\text {Gnet }}\right)$ is calculated by Equation (15):

$$
\dot{W}_{\text {Gnet }}=\dot{W}_{C}+\dot{W}_{g \cdot T}
$$

The output power from the gas turbine $\left(P_{G) \text { net }}\right)$ is expressed as Equation (16):

$$
P_{G) \text { net }}=2 \times\left[\left(\dot{W}_{C}+\dot{W}_{g . T}\right) \eta_{M . G T}\right] \times \eta_{G . G T}
$$

The specific fuel consumption $(S F C)$ is determined by

$$
\text { S.F.C }=\frac{3600}{A F R \times \dot{W}_{\text {Gnet }}}
$$

The heat supplied is also expressed as Equation (18):

$$
\dot{Q}_{a d d}=\dot{m}_{g} C p_{g} T_{4}-\dot{m}_{a} C p_{a} T_{2}
$$

The GTefficiency $\left(\eta_{t h) G T}\right.$ ) can be determined by Equation (19):

$$
\eta_{\text {th }) G T}=\frac{-\dot{W}_{\text {Gnet }}}{\dot{Q}_{a d d}}
$$

The heat rate $(H R)$ can be expressed as Equation (20):

$$
H R=\frac{3600}{\eta_{t h) G T}}
$$

The overall efficiency ( $\eta_{\text {over }) G T}$ ) can be determined by Equation (21)

$$
\eta_{\text {over }) G T}=\frac{-\dot{W}_{n e t}}{\dot{m}_{f} \times C . V}
$$

\section{Results and Discussion}

The results validation for similar design conditions is presented in Table 1.

1) Effect of Ambient Temperature (T1)

Figure 2 shows that increasing of inlet air temperatures results in a decrease in the thermal efficiency of the cycle. Increase of regenerative effectiveness results in increase of the thermal efficiency of the gas turbine cycle.

Figure 3 represents the effect of inlet air (ambient) temperature on the thermal

Table 1. Gas turbine results validation.

\begin{tabular}{ccc}
\hline Plant location & ZAWIA \\
\hline Manufacture & & ALSTOM \\
\hline Output power $[\mathrm{MW}]$ & program & 119.32 \\
& Data & 118 \\
Exhaust temperature $\left[{ }^{\circ} \mathrm{C}\right]$ & program & 556 \\
& Data & 550 \\
\hline
\end{tabular}




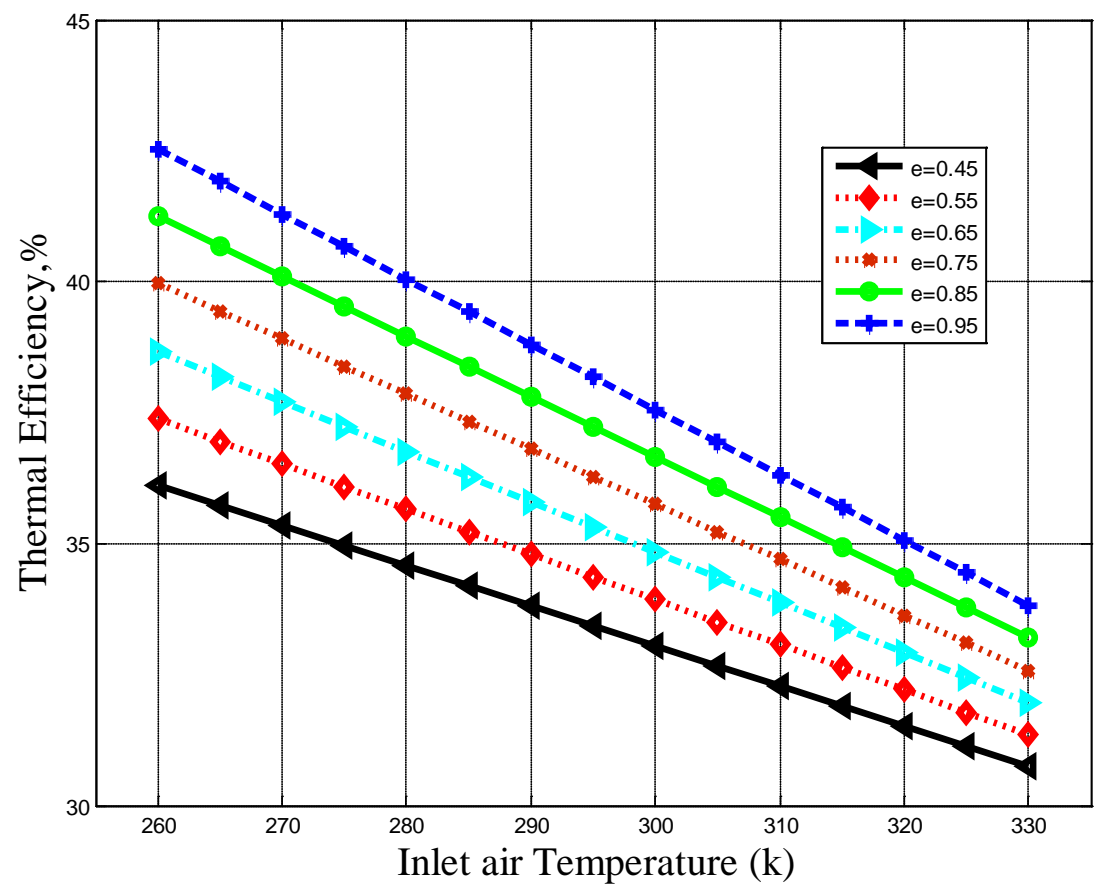

Figure 2. Gas turbine cycle thermal efficiency versus air (ambient) temperature for different regenerative effectiveness.

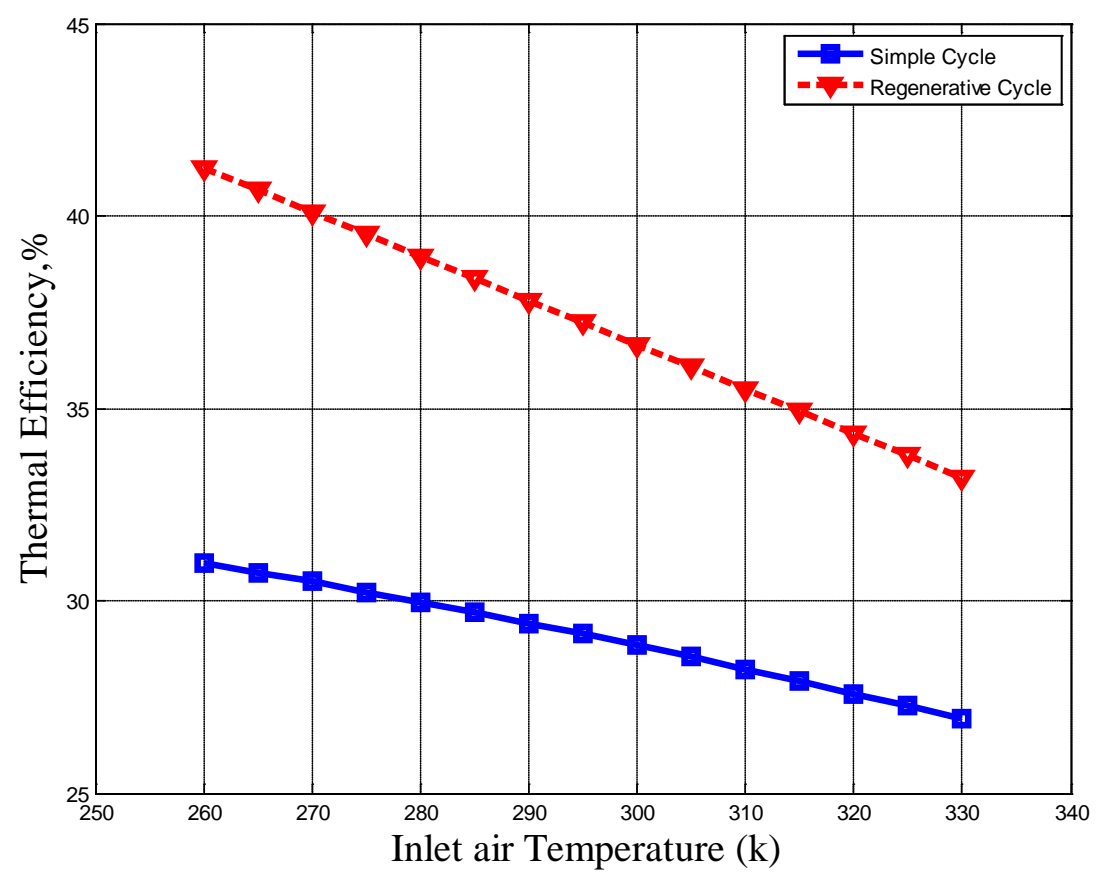

Figure 3. Effect of ambient temperature on thermal efficiency for simple and regenerative cycle.

efficiency of a simple gas turbine cycle and gas turbine cycle including regeneration. As shown in Figure 3 adding regeneration to the gas turbine cycle results in increase of the thermal efficiency of the gas turbine cycle. The variation of specific fuel consumption with ambient temperature and compression ratio is also shown in Figure 4. It shows that at constant compression ratio increases of 


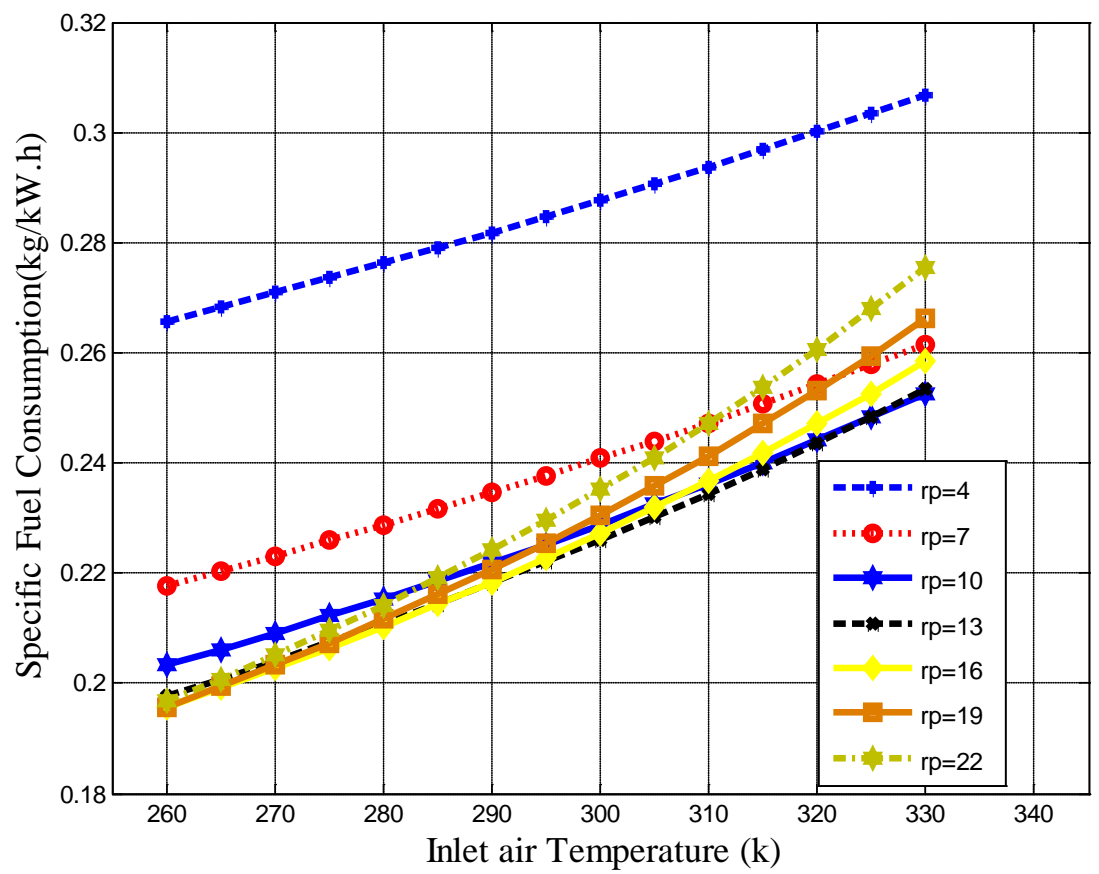

Figure 4. Influence of the ambient temperature on the SFC for different compression ratios.

the inlet air temperature results in an increase in the specific fuel consumption. This could be interpreted as follow: when the ambient temperature decreases, the air mass flow rate inlet to compressor increases, and this causes the specific fuel consumption to increase.

As shown in Figure 4, at constant ambient air temperature, increasing of the compression ratio results in a decrease in specific fuel consumption.

2) Effect of Compression Ratio $\left(r_{p}\right)$

In general, in gas turbine cycles, the increase of the compression ratio results in an increase in the thermal efficiency of the cycle, as shown in Figure 5 and Figure 6 . The thermal efficiency of the gas turbine cycle increases sharply between 0.15 to 0.3 in the low range of compression ratio between ranges between 2 and 6 . Then the thermal efficiency increases gradually in the higher range of compression ratio between 6 and 22. Figure 5 represent the effect of compression ratio on the cycle thermal efficiency for different inlet air temperatures. Figure 5 shows that at constant air temperature, the thermal efficiency increases with increasing of the compression ratio.

Figure 6 shows the effect of the compression ratio on the simple gas turbine cycle thermal efficiency and on the thermal efficiency of regenerative cycle. The thermal efficiency increases with increase of compression ratio in both cases.

Figure 7 represents the effect of compression ratio on the specific fuel consumption (SFC) for different inlet air temperature (T1) ranges between $268 \mathrm{k}$ and $328 \mathrm{k}$. The general trend is similar for different inlet air temperatures. The specific fuel consumption decreases sharply in the range of compression ratio ranges between 0.2 and 0.6 , then it becomes stable in the range of compression ratio between 6 and 22, as shown in Figure 7. Increasing of inlet air temperature 


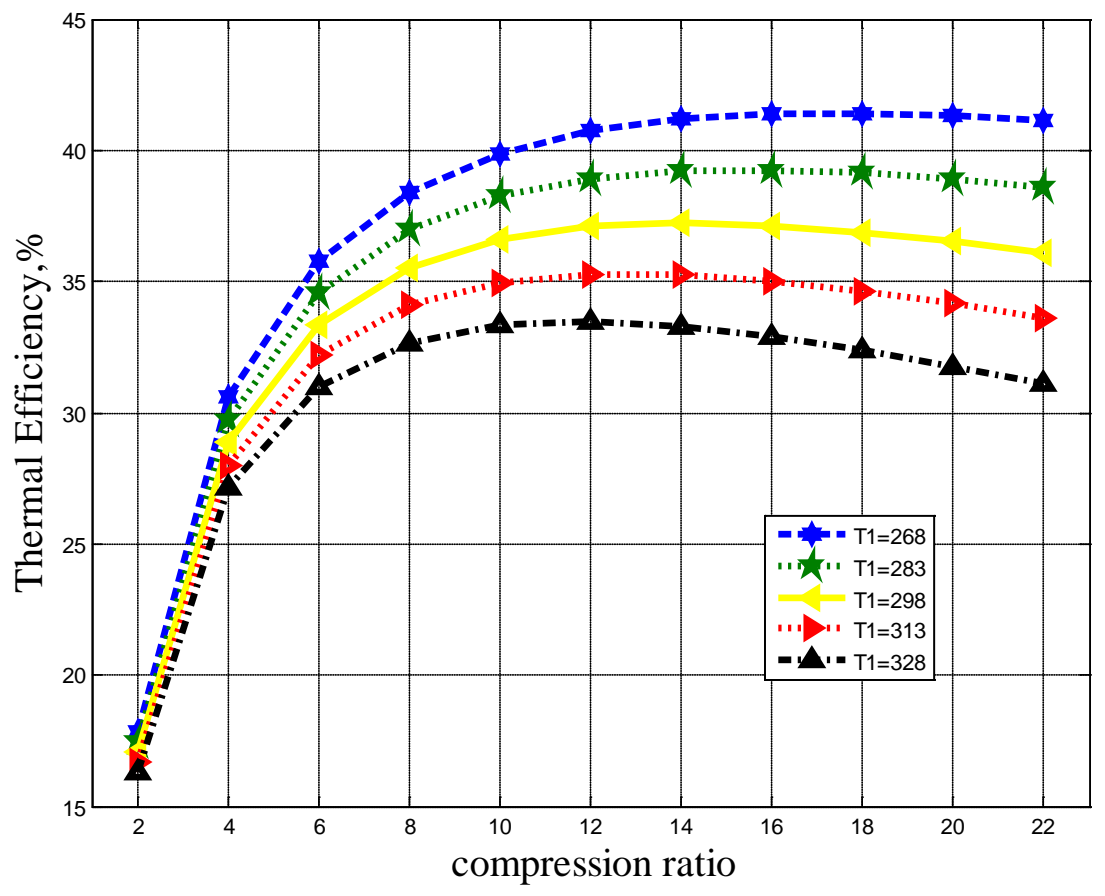

Figure 5. Thermal efficiency versus compression ratio for different inlet air temperature.

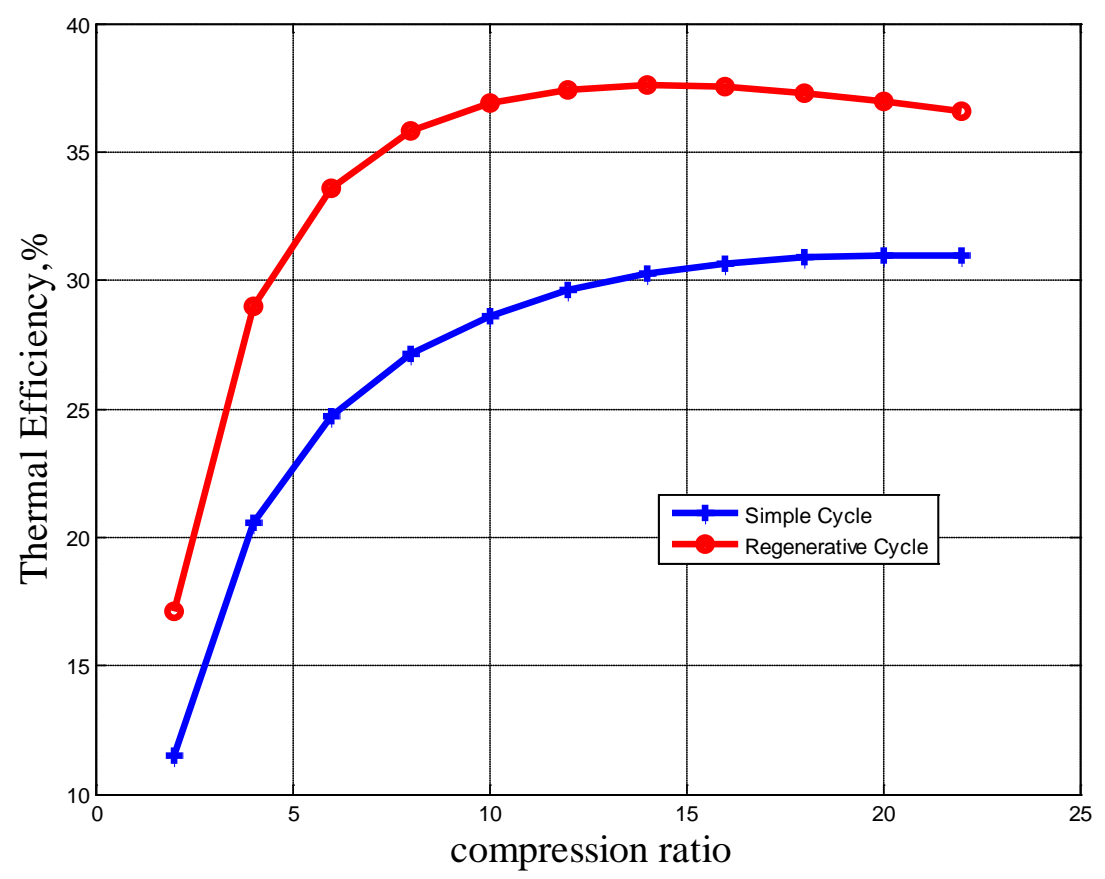

Figure 6. Effect of compression ratio on thermal efficiency for simple and regenerative cycle.

results in increase of specific fuel consumption, as shown in Figure 7.

Figure 8 shows the variation of specific fuel consumption (SFC) in the range of 0.22 to 0.6 with the compression ratio ranges between 2 and 22 at different regeneration effectiveness $(\varepsilon)$ ranges between 0.45 and 0.95 . The general trend is the specific fuel consumption decreases sharply in low range of compression ratio 


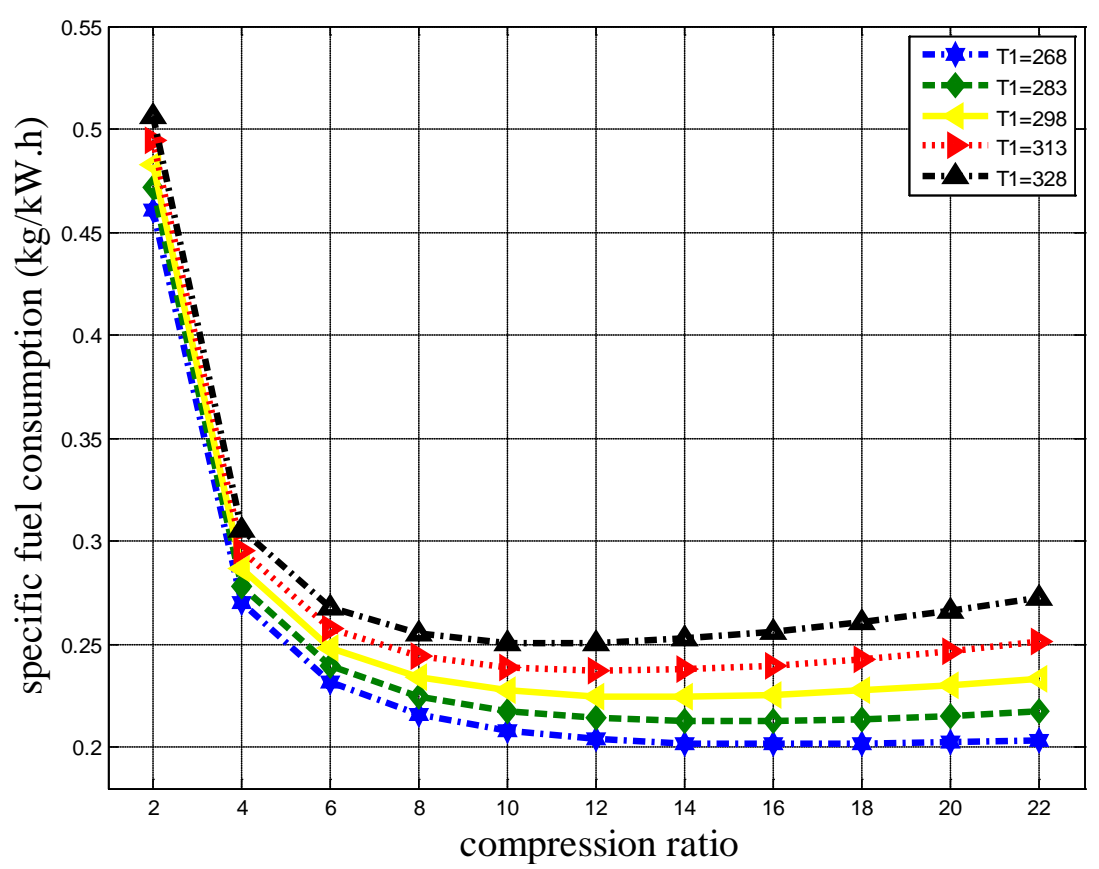

Figure 7. Influence of compression ratio on specific fuel consumption (SFC) for different inlet air temperatures.

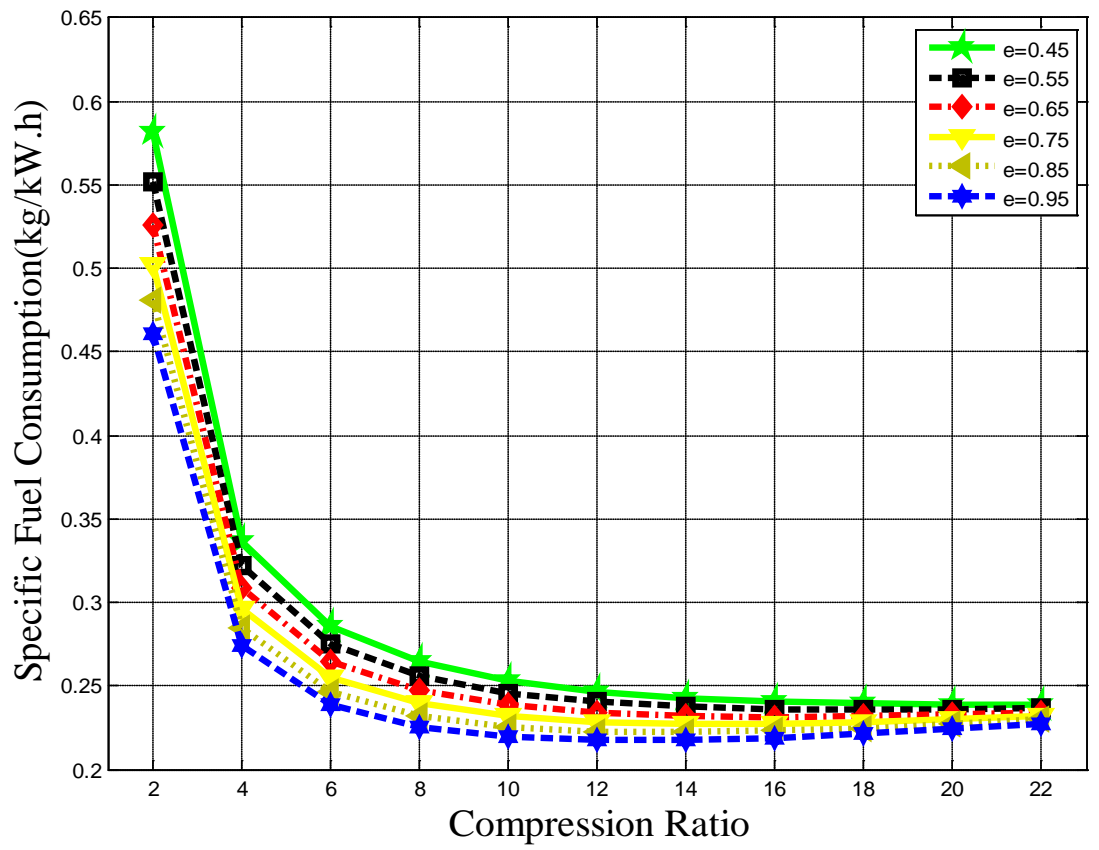

Figure 8. Influence of compression ratio on specific fuel consumption at different regeneration effectiveness.

ranges between 2 and 6 . Then it becomes stable in the range of compression ratio between 6 and 22. Increasing of regeneration effectiveness results in a decrease in the specific fuel consumption, as shown in Figure 8.

Figure 9 shows the effect of regeneration effectiveness on the thermal efficiency of the cycle for different compression ratios. Increasing of regeneration effectiveness results in an increase in the thermal efficiency of the gas turbine cycle. 


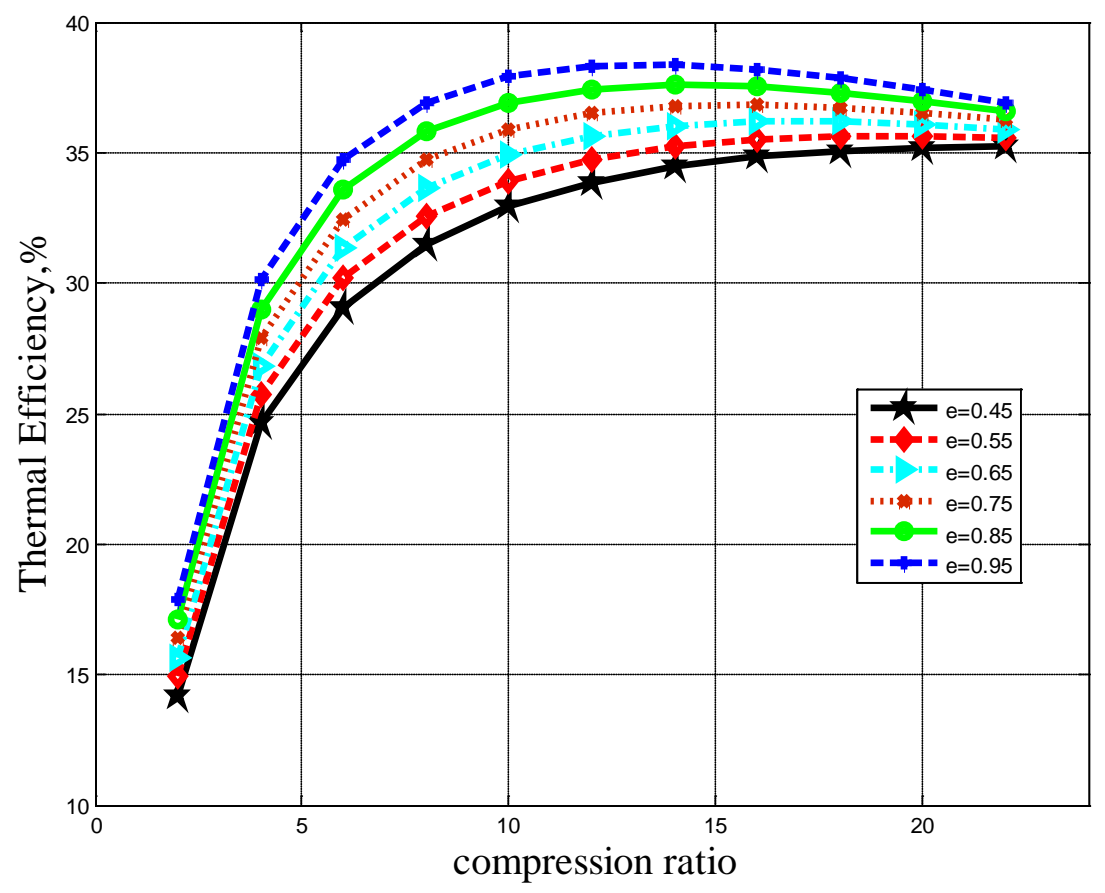

Figure 9. Effect of compression ratio and reg. effectiveness on thermal efficiency.

\section{Conclusions}

An intensive parametric study in gas turbine cycle including regenerative is presented in this paper.

The parametric study showed that the compression ratio and inlet air temperature had a major effect on the thermal efficiency of a simple and generative gas turbine cycles. Adding regeneration to simple gas turbine cycle results in the increase of thermal efficiency of the cycle. Increasing of compression ratio results in the increase of the thermal efficiency of simple and regenerative gas turbine cycle.

\section{References}

[1] Nag, P.K. (2008) Power Plant Engineering. Tata McGraw-Hill Publishing Company Limited, New Delhi.

[2] Cengel, A.Y. and Boles, A.M. (2008) Thermodynamics: An Engineering Approach. McGraw-Hill, New York.

[3] Mahmood, F.G. and Mahdi, D.D. (2009) A New Approach for Enhancing Performance of a Gas Turbine (Case Study: Khangiran Refinery). Applied Energy, 86, 2750-2759. http://dx.doi.org/10.1016/j.apenergy.2009.04.017

[4] Wang, F.J. and Chiou, J.S. (2004) Integration of Steam Injection and Inlet Air Cooling for a Gas Turbine Generation System. Energy Conversion and Management, 45, 15-26. http://dx.doi.org/10.1016/S0196-8904(03)00125-0

[5] Ameri, M. (2004) The Study of Capacity Enhancement of The Chabahar Gas Turbine Installation Using an Absorption Chiller. Applied Thermal Engineering, 24, 59-68. http://dx.doi.org/10.1016/S1359-4311(03)00239-4

[6] Ibrahim, T.K. and Rahman, M.M. (2010) Effects of Operation Condition on Performance of a Gas Turbine Power Plant. Procedia Engineering, 15, 42164223. http://dx.doi.org/10.1016/j.proeng.2011.08.791 
[7] Sánchez-Orgaz, S., Medina, A. and Hernández, A.C. (2012) Maximum Overall Efficiency for a Solar-Driven Gas Turbine Power Plant. International Journal of Energy Research, 37, 1580-1591.

[8] Mohapatra, A.K. and Prasad, L. (2012) Parametric Analysis of Cooled Gas Turbine Cycle with Evaporative Inlet Air Cooling. International Journal of Scientific \& Engineering Research, 3, Issue 3.

[9] Moran, M.J. and Shapiro, H.N. (2008) Fundamentals of Engineering Thermodynamics. John Wiley \& Sons, INC, New York.

[10] Rahman, M.M., Ibrahim, T.K., Taib, M.Y., Noor, M.M., Kadirgama, K. and Rosli, A.B. (2010) Thermal Analysis of Open-Cycle Regenerator Gas-Turbine PowerPlants. WASET, 68, 94-99.

Submit or recommend next manuscript to SCIRP and we will provide best service for you:

Accepting pre-submission inquiries through Email, Facebook, LinkedIn, Twitter, etc. A wide selection of journals (inclusive of 9 subjects, more than 200 journals)

Providing 24-hour high-quality service

User-friendly online submission system

Fair and swift peer-review system

Efficient typesetting and proofreading procedure

Display of the result of downloads and visits, as well as the number of cited articles Maximum dissemination of your research work

Submit your manuscript at: http://papersubmission.scirp.org/

Or contact epe@scirp.org 